DOI: http://dx.doi.org/10.33846/hn50407

http://heanoti.com/index.php/hn

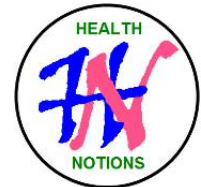

RESEARCH ARTICLE

URL of this article: http://heanoti.com/index.php/hn/article/view/hn50407

\title{
Percutaneous Coronary Intervention in Post-Infarction Ventricular Septal Rupture
}

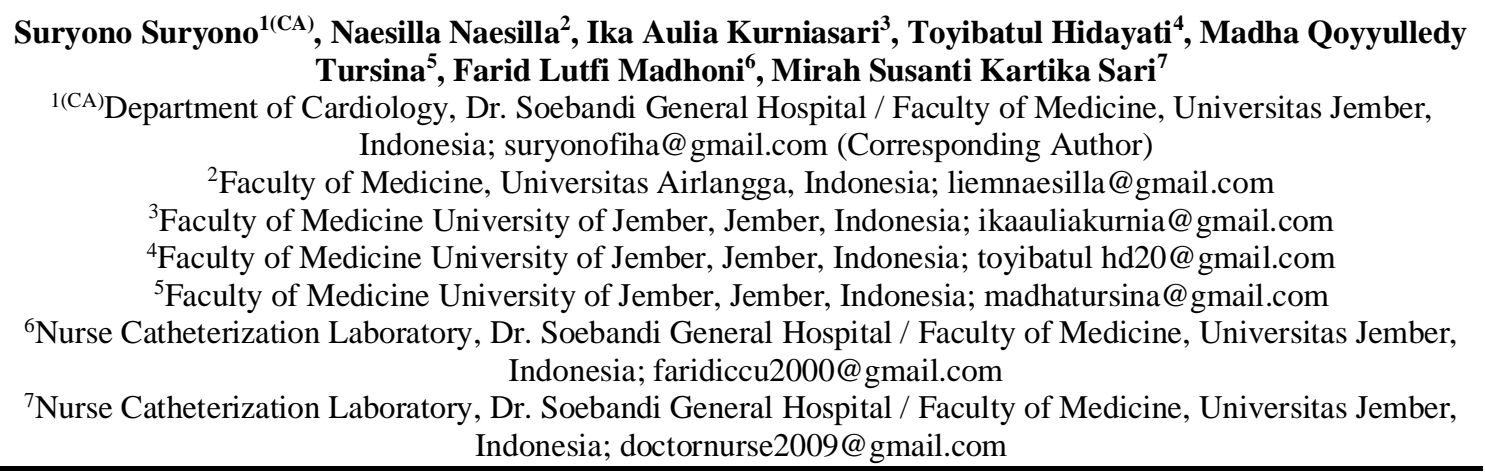

\section{ABSTRACT}

Background: Ventricular septal rupture (VSR) is a fatal mechanical complication following acute myocardial infarction (AMI). The definitive treatment remains surgical repair, however several aspects are still debatable, including the timing of surgery. Patient's refusal of treatment and lack of medical facilities put other challenges in management of VSR. Case presentation: A-48-year-old male with a history of diabetes mellitus and hypertension came with a late-presentation anterior AMI, and refused the reperfusion therapy. By the third day, he developed VSR and cardiogenic shock. The patient was also against any referral plan for further therapy. Hemodynamic status was optimally controlled with vasopressor and inotropic agents. The patient was discharged with a grade II-III New York Heart Association (NYHA) on the tenth day. In follow up evaluation a week later, the patient presented limb swelling and functional NYHA class III-IV. The patient agreed to received percutaneous coronary intervention (PCI). Drug eluting stent (DES) in left anterior descending (LAD) coronary artery was implanted successfully without defect closure. Follow-up after 12-months revealed no signs or symptoms of decompensated heart failure.

Keywords: ventricular septal rupture; percutaneous coronary intervention; acute myocardial infarction

\section{INTRODUCTION}

Major complications of acute myocardial infarction (AMI) include heart failure, arrhythmias, embolism, inflammation, and mechanical complications. ${ }^{(1)}$ One of the mechanical complications involving ventricular septal rupture (VSR), a rare fatal complication. The incidence of post-infarction VSR is $1-2 \%$. This number has dropped significantly $(0.17-0.31 \%)$ since the development of effective reperfusion therapy. ${ }^{(1,2)}$ Its mortality rate is $24-87 \%$ and $90 \%$ in patients with and without definitive surgery, respectively. ${ }^{(3,4,5)}$ Defect size, hemodynamic status, and comorbidities may predispose the mortality on VSR cases. ${ }^{(3,4)}$

Surgical closure should be performed immediately in large VSRs $(\geq 15 \mathrm{~mm})$ to prevent embolizations. Meanwhile, amplatzer closure is recommended for small-medium VSRs $\leq 15 \mathrm{~mm}$ to stabilize the patients' hemodynamic and may also be used as a temporary correction. ${ }^{(6)}$ The American College of CardiologyAmerican Heart Association recommends immediate closure surgery regardless of the hemodynamic status. Combination of definitive VSR therapy with other therapeutic options such as reperfusion therapy with the primary percutaneous coronary intervention ( $\mathrm{pPCI}$ ) is frequently used to overcome the high mortality rate postoperatively. Inadequate stenting will require coronary artery bypass grafting (CABG) to prevent the risk of surgical complications and continued with the defect closure. ${ }^{(3,7,8,9)}$ Therefore, management of VSR involves a multidisciplinary approach. Meanwhile, patient delay (refusal of treatment) and lack of medical facilities put other challenges in VSR management. This article reported a post-infarction VSR patient who received the percutaneous coronary intervention (PCI) without defect closure. 


\section{METHODS}

A-48 year-old hypertensive and diabetic male sought medical care to the Emergency Department (ED) due to increasing-intensity chest pain lasting for 13 hours. He had the blood pressure of 160/93 $\mathrm{mmHg}$, heart rate $(\mathrm{HR})$ of $100 \mathrm{bpm}$, the temperature of $36.50 \mathrm{C}$, and respiration rate $(\mathrm{RR})$ of $20 \mathrm{x} / \mathrm{min}$ and peripheral oxygen saturation ( $\mathrm{SpO} 2$ ) of $96 \%$ (room air). He had no history of smoking or heart disease.

\section{RESULTS}

Initial electrocardiogram showed normal sinus rhythm, HR 105 bpm, normal axis, ST-segment elevation in leads II, III, aVF, V1-V6, concluded as anteroinferior STEMI and the laboratory tests showed positive cardiac troponin. The chest X-ray showed cardiomegaly without any signs of pulmonary oedema (Figure 1).

The patient was diagnosed with anteroinferior ST-segment elevation myocardial infarct (STEMI). Despite extensive education, the patient refused reperfusion therapy. Thus, the patient was treated with the standard medication, including loading dose $300 \mathrm{mg}$, loading dose clopidogrel $300 \mathrm{mg}$, atorvastatin $40 \mathrm{mg}$, glimepiride $1 \mathrm{mg}$, and IV nitroglycerin $10 \mathrm{mcg} / \mathrm{min}$ and loading dose enoxaparin $0.3 \mathrm{cc}$ IV followed by 2 x 0.6 cc subcutaneously.

On the 3rd day, the patient experienced cardiogenic shock with BP of 80/60 mmHg, HR $120 \mathrm{bpm}$, RR 30 $\mathrm{x} / \mathrm{min}$, with cold clammy extremities (Killip score IV). A new 3/6 pansystolic murmur was found in the parasternal linea ICS IV 3/6. Echocardiography showed a VSR sized $0.98 \mathrm{~cm}$ in diameter and a left ventricular ejection fraction of $48 \%$ (Figure 3). The final diagnosis was anteroinferior STEMI complicated with VSR and cardiogenic shock. Nitroglycerin IV was discontinued, and the patient received dobutamine started at 10 $\mathrm{mcg} / \mathrm{min}$ and norepinephrine started at $0.5 \mathrm{mcg} / \mathrm{min}$.

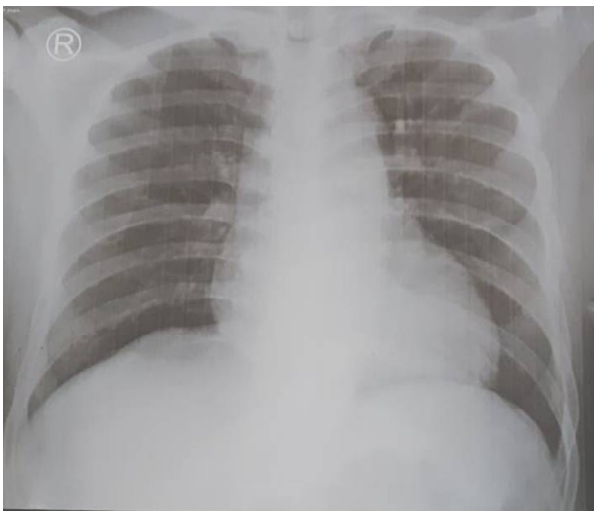

Figure 1. Chest X-ray showed cardiomegaly

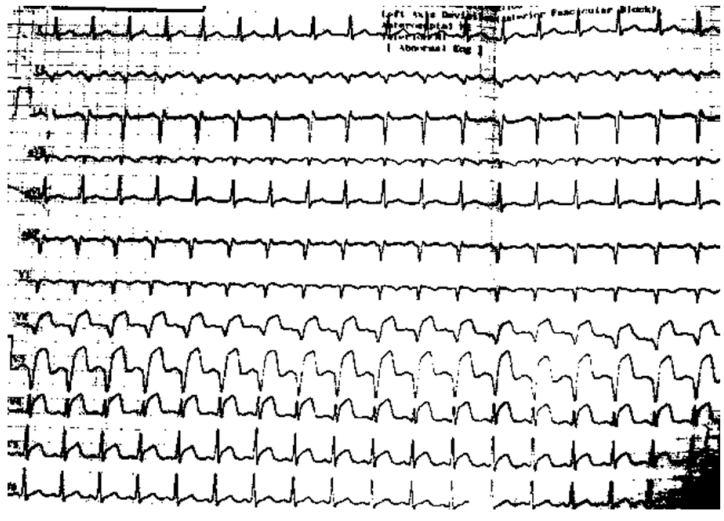

Figure 2. Electrocardiogram in third day of admission

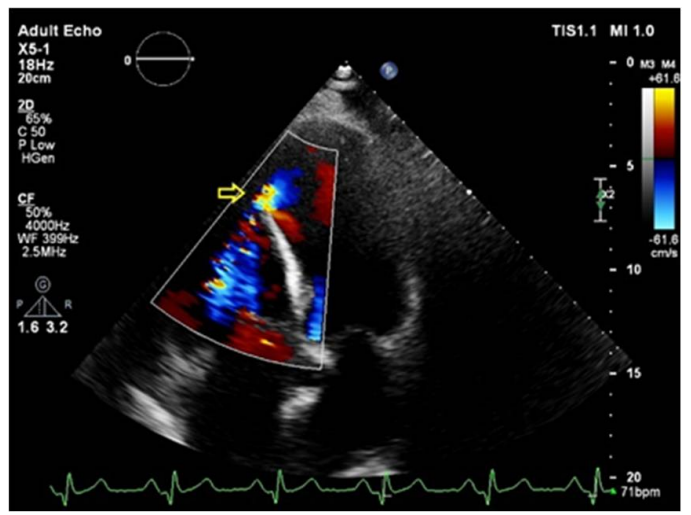

Figure 3. Four chamber echocardiography showed the presence of a VSR type with a diameter of $0.98 \mathrm{~cm}$ and the left ventricular ejection fraction of $48 \%$

The patient's hemodynamic status gradually improved with vasopressors, subsequently, acute heart failure had resolved. On day-5, his blood pressure was $110 / 70 \mathrm{mmHg}$, the patient was treated with furosemide 1 x $20 \mathrm{mg}$ and ramipril started 1 x 1,25 mg. Dobutamine and norepinephrine were gradually tapered and discontinued the next day. The following day, he received bisoprolol 1 x $1.25 \mathrm{mg}$, spironolactone 1 x $25 \mathrm{mg}$ and 
increased dose of ramipril ( 1 x $2.5 \mathrm{mg}$ ). On day 10 of hospitalization, the patient was no longer having complaints and discharged.

Seven days after hospital discharge, the patient developed symptoms of heart failure: shortness of walking and had lower limbs swelling. The patient was classified as NYHA Functional Class III-IV. The patient and his family were re-informed about the condition and willing to be having PCI. Once the hemodynamic status stabilized, the coronary angiography was performed via the right femoral artery using 6 Fr sheath. It revealed insignificant stenosis in the proximal right coronary artery and left circumflex artery. Critical stenosis was shown in the proximal LAD (Figure 4). DES was placed in the proximal left anterior descending artery (LAD) using a guiding catheter launcher JL 4.0/6Fr, wire run-through NS, pre dilatation using a $2.0 \times 20 \mathrm{~mm}$ Across Up balloon inflated up to $10 \mathrm{~atm}$. After recanalization and pre-dilatation with a balloon in the left anterior descending artery, a $3.0 \times 20 \mathrm{~mm}$ CRE8 stent was placed to expand it to 14 atm and evaluated by angiogram (Figure 5). No complication emerged during and after PCI.

The angiogram also showed the extent of LAD down to the heart base therefore stenosis in the proximal part of the LAD might cause extensive necrotizing myocardial tissue. Following the PCI procedure, the patient had no more complaints, his hemodynamic status remained stable and the patient was discharged. Follow up evaluation at 12 months showed no signs and symptoms of any complications.

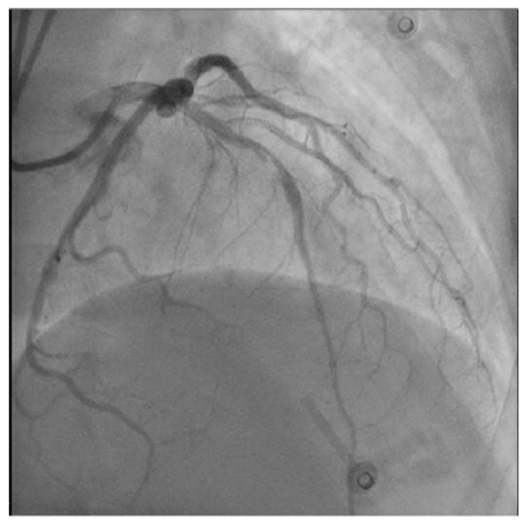

Figure 4.Coronary angiogram examination (pre stent) showed critical stenosis in the left anterior descending proximal artery
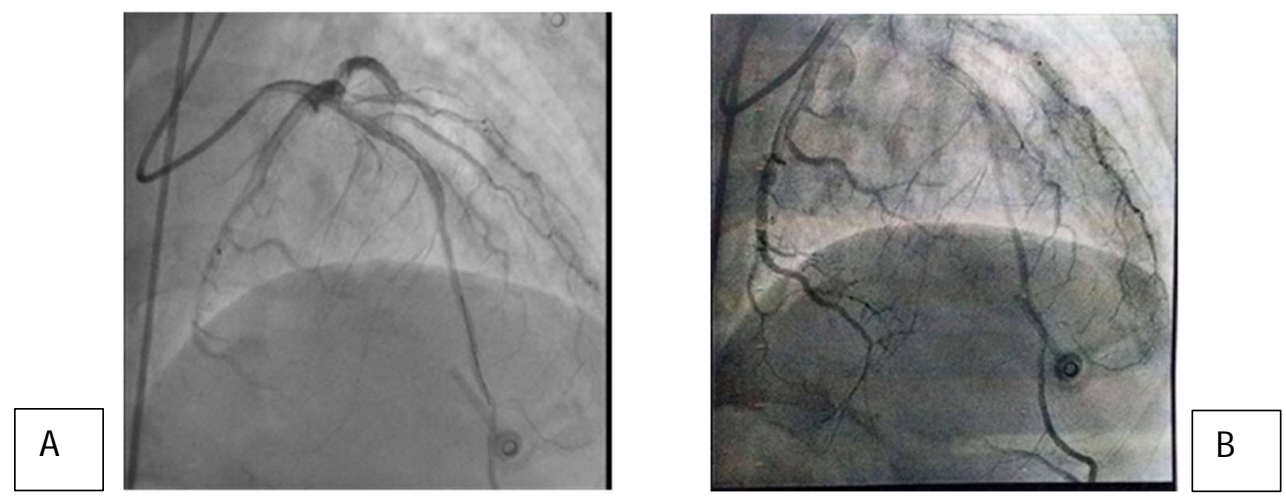

Figure 5. A. Coronary angiogram (post stent). B. Left anterior descending artery (LAD) appears long to the basal

\section{DISCUSSION}

Ventricular Septal Rupture (VSR) is an interventricular septum defect due to ischemic necrosis following STEMI. ${ }^{(1)}$ This complication is rarely found, nevertheless, it carries high mortality risk. ${ }^{(2)}$ Only a few studies had reported VSR and the definitive management of VSR is still widely debated. As mentioned above, the American College of Cardiology-American Heart Association recommends immediate closure surgery regardless of the hemodynamic status. ${ }^{(10)}$ Meanwhile, the European Society of Cardiology guidelines stated that optimal time for defect closure was yet to determined. ${ }^{(5)}$

Previous studies on VSR observed that closing the defect could reverse the affected hemodynamic status (mainly due to left-to-right shunt). ${ }^{(11,2,12,13)}$ Lack of expertise and medical sources are challenging for the 
clinicians in regional health care centres. Several predisposing factors of VSR of this patient included the presence of comorbidities such as diabetes mellitus, hypertension, no history of smoking, and anteroinferior STEMI. ${ }^{(11,5)}$ VSRs following anterior STEMI are usually simple type and located in the apical septum, whereas VSRs from inferior STEMI are usually extensive complex type and located in the basal part of the septum. Inferior STEMIs are frequently complicated with cardiogenic shock. ${ }^{(5)}$

The angiography showed an anatomical anomaly of the coronary artery in this patient. Long LAD was found extending to the base of the heart (Figure 5B). Approximately, only $1.5 \%$ of angiogram showed an anomaly in the coronary artery. ${ }^{(14)}$ Rupture is a result of tissue necrosis extending to the interventricular septum. This event attracted neutrophil infiltration into the necrotic tissue leading to thinning of the septum. Those neutrophils triggered the apoptosis and released the lytic enzymes that accelerate the degradation of necrotic tissue. ${ }^{11}$ Several studies observed that VSR frequently occur 3-5 days post-infarction. ${ }^{(14,15,5)}$ This finding was in concordance with our case whose VSR was found on the 3rd-day post-infarction. The longer left anterior descending artery, the more tissue it vascularizes. It means that occlusion in the proximal part of long LAD would affect a wider area. However, the association between this anomaly and VSR was not yet established, possibly related to unknown coronary artery anomalies or unreported cases.

As shown before, the patient refused the definitive therapy, only to find that he returned with unstable hemodynamic a week after discharged. Hemodynamic stabilization was the priority, followed by reperfusion therapy via PCI. PCI was aimed to restore the flow in the coronary vessels and prevent the extension of ischemic tissue. ${ }^{(16)}$ Once the stent implanted, the coronary blood flow will continue to provide perfusion to the tissue and cease the apoptotic process and expansion of the necrotic tissue. The remaining non-ischemic tissue also endures the inflammatory response due to the presence of necrotic tissues. As a result, cell regenerates and scar forms as fibrous connective tissue in the area of necrosis. ${ }^{(17)}$ Necrotic cardiomyocyte attracts cellular changes including cardiac hypertrophy, apoptosis, necrosis, increased collagen production, and fibroblast proliferation. Fibroblasts predominate since early proliferation phase particularly in the infarct region and may display proliferative, migratory, and secretory myofibroblast features. ${ }^{(18)}$ Myofibroblasts produced most of the interstitial collagen (initially type III and later type I collagen). Collagen deposition was essential to increase tensile strength and prevent further rupture. Myofibroblasts increased the secretion of fibronectin (FN) and various cellular matrix proteins which further increase myofibroblast migration. ${ }^{(19)}$ Furthermore, angiogenic signalling stimulates the proliferation and infiltration of endothelial cells leading to the formation of microvascular tissue to the infarct area. ${ }^{(20,21)}$ It was essential to supply myofibroblasts with adequate oxygen and nutrients during the remodelling process. Following the formation of a collagen-based matrix at the infarct site, the growth factors, matrix cell proteins, and myofibroblast activity would decrease. ${ }^{(22,18,21)}$ Type III collagen will eventually be replaced by type I collagen. Type I collagen is modified further by cross-linking catalyzed by lysyl oxidases (LOX). Expression of the four isoforms of lysyl oxidases was increased in the infarct area and the border zone 3-7 days post-myocardial infarction. ${ }^{(23)}$ The cross-linking of the collagen fibres increased the tensile strength and formed scar contraction The presence of fibrotic tissue formation prevented the extension of defect size. ${ }^{(24)}$

The extensive ischemia and lack of collateral circulation accelarated the forming of VSR, resulting in short period of time between MI and VSR. The deterioration of the patient's hemodynamic status during the formation of VSR occurred due to unexpected left-to-right shunt. Fibrosis tissue, collateralization, small defect size $(<15 \mathrm{~mm})$, and reperfusion therapy to restore adequate coronary blood flow might play some roles, in this case, allowing an adaptation to the new intracardiac system and maintaining the hemodynamic stability. ${ }^{(25,5)}$

\section{CONCLUSION}

Reperfusion therapy via percutaneous coronary intervention (PCI) may improves hemodynamic status in the presence of post-infarction VSR. Several factors need to be considered in choosing therapeutical approach, such as the size of the defect, the hemodynamic status of the patient, the availability of health care facilities or sources, and also timing (since onset of infarction). Regular follow up is necessary to monitor the defect size, hemodynamic status, or long-term complication in these patients.

\section{REFERENCES}

1. Kutty RS, Jones N, Moorjani N. Mechanical Complications of Acute Myocardial Infarction. Cardiology Clinics. 2013;31(4):519-531. doi: 10.1016/j.ccl.2013.07.004

2. Jones BM, Kapadia SR, Smedia NG, Robich M, Tuzcu EM, Menon V, Krishnaswamy A. Ventricular septal rupture complicating acute myocardial infarction: A contemporary review. European Heart Journal. 2014;35(31):2060-2068. doi: 10.1093/eurheartj/ehu248

3. Radosavljević-Radovanović M, Radovanovic N, Arandjelovic A, Mitrovic P, Uscumlic A, Stankovic G. Urgent hybrid approach in treatment of the acute myocardial infarction complicated by the ventricular 
septal rupture. Srpski Arhiv za Celokupno Lekarstvo. 2014;142(3-4):226-228. doi: 10.2298/SARH1404226R

4. Wahjono A, Anjarwani S. Manajemen Ruptur Septum Ventrikel Pasca Infark Miokard Akut di Rumah Sakit tanpa Fasilitas Bedah. 2017;29(3):271-275.

5. Shafiei I, Jannati F, Jannati M. Optimal Time Repair of Ventricular Septal Rupture Post Myocardial Infarction. Journal Of The Saudi Heart Association. 2020;32:288-294.

6. Pang YK, Sin YK, Lim CH, Tan TE, Lim SL, Chao V, et al. Outcome and survival analysis of surgical repair of post-infarction ventricular septal rupture. Journal of Cardiothoracic Surgery. 2013;8:44.

7. Mangkoesoebroto AP, Sungkar S, Sugiri S, Rifqi S. Ventricular septal rupture pasca infark miokard akut: diagnosis dini dan tatalaksana. Medica hospitalica. 2018;5(1):59-65.

8. Zhi-ping Z. Heart and Circulation Ventricular Septal Rupture with Acute Myocardial Infarction : Primary Percutaneous Coronary Intervention and Delayed Transcatheter Closure of The Rupture. Scientifict Open Access Journal. 2018;2(1):020.

9. Hernawati IE. Long term survival of ventricular septal rupture (VSR) closure concomitant with CABG in post-acute myocardial infarction patient. Cardiovascular and Cardiometabolic Journal (CCJ). 2020;1(2):50. doi: 10.20473/ccj.v1i2.2020.50-56

10. O'Gara PT, Kushner FG, Ascheim DD, Casey ED, Chung MK, de Lemos JA, et al. 2013 ACCF/AHA guideline for the management of ST-elevation myocardial infarction: a report of the American College of Cardiology Foundation/American Heart Association Task Force on Practice Guidelines. J Am Coll Cardiol. 2013;61:e78-140.

11. Birnbaum Y, Michael CF, Blanche C, Robert JS. Ventricular septal rupture after acute myocardial infarction. The New England Journal of Medicine. 2002.;47(18):1-7.

12. Asai T. An update review on postinfarction ventricular septal rupture. Journal of Coronary Artery Disease. 2019;25(1): 16-20.

13. Mubarik A, Iqbal M. Ventriular Septal Rupture. 2020.

14. Watanabe T, Tamura A, Torigoe K. Unusual long left anterior descending coronary artery with a posterior "ascending" branch. International Journal of Cardiology. 2013;163(1):e17-e18.

15. Malhotra A, Patel K, Sharma P, Wadhawa V, Madan T, Khandeparkar J, Shah K, Patel S. Techniques, Timing \& Prognosis of Post Infarct Ventricular Septal Repair: a Re-look at Old Dogmas. Braz J Cardiovasc Surg. 2017;32(3):147e55. doi: https://doi.org/10.21470/1678-9741-2016-0032

16. Loscalzo J. Harrison's Cardiovascular Medicine 2nd Edition. In: Faxon DP, Bhatt DL. Percutaneous Coronary Interventions and Other Interventional Procedures. Chapter 36. McGrawHill Education; 2013.

17. Price SA, Wilson LM. Patofisiologi: Konsep Klinis Proses-proses Penyakit. Jakarta: EGC; 2012.

18. Shinde AV, Frangogiannis NG. Fibroblasts in myocardial infarction: a role in inflammation and repair. J Mol Cell Cardiol. 2014;70:74-82.

19. Frangogiannis NG. Matricellular proteins in cardiac adaptation and disease. Physiol Rev. 2012;92:635688.

20. Jaffer FA, Sosnovik DE, Nahrendrof M, Weissleder R. Molecular imaging of myocardial infarction. J Mol Cell Cardiol. 2006;41:921-933.

21. Frangogiannis NG. The inflammatory response in myocardial injury, repair, and remodelling. Nat Rev Cardiol. 2014;11:255-265.

22. Van den Borne SW, Diez J, Blankesteijn WM, Verjans J, Hofstra L, Narula J. Myocardial remodeling after infarction: the role of myofibroblast. Nat Rev Cardiol. 2010;7:30-37.

23. Gonzalez-Santamaria J, Villalba M, Busnadiego O, Lopez-Olaneta MM, Sandoval P, Snabel J, LopezCabrera M, Erler JT, Henamaijer R, Lara-Pezzi E, Rodriguez-Pascual F. Matrix cross-linking lysyl oxidases are induced in response to myocardial infarction and promote cardiac dysfunction. Cardiovasc Res. 2016;109:67-78.

24. Talman V, Ruskoaho H. Cardiac fibrosis in myocardial infarction-from repair and remodeling to regeneration. Cell Tissues Res. 2016;365:563-581.

25. Malhotra A, Patel K, Sharma P, Wadhawa V, Madan T, Khandeparkar J, Shah K, Patel S. Techniques, Timing \& Prognosis of Post Infarct Ventricular Septal Repair: a Re-look at Old Dogmas. Braz J Cardiovasc Surg. 2017;32(3):147e55. doi: https:// doi.org/10.21470/1678-9741-2016-0032 